Artigo Original

\title{
Educação física, desenvolvimento e inovação: o argumento da hélice tríplice
}

\author{
Carlos Alberto Figueiredo da Silva ${ }^{13}$ \\ José Pedro Sarmento Rebocho Lopes ${ }^{2}$ \\ Jacques de Araújo Netto ${ }^{3}$ \\ ${ }^{1}$ Centro Universitário Augusto Motta, Rio de Janeiro, RJ, Brasil \\ ${ }^{2}$ Universidade do Porto, Portugal \\ ${ }^{3}$ Universidade Salgado de Oliveira, São Gonçalo, RJ, Brasil
}

\begin{abstract}
Resumo: Este estudo analisa dados presentes no Portal da Inovação do Ministério da Ciência e Tecnologia do Brasil, com o objetivo de compreender o processo de inovação na área de educação física. Utiliza-se o argumento hélice tríplice como referencial teórico para avaliar a sinergia entre universidade-governoempresa no campo da pesquisa em educação física. A metodologia utilizada pautou-se pela pesquisa bibliográfica e documental. Os resultados permitem inferir que a área de pesquisa em educação física pode ser caracterizada como tipicamente multidisciplinar. Constata-se um número expressivo de pesquisadores e de grupos de pesquisa. Entretanto, não existem empresas vinculadas. A não participação da empresa indica que a educação física está distante do setor produtivo, o que ressalta a sua incapacidade, hoje, em captar recursos para a pesquisa junto a esse setor, bem como envolvê-lo em esquemas que viabilizem projetos de inovação e desenvolvimento a partir de ações de pesquisa.
\end{abstract}

Palavras-chave: Educação Física. Políticas e Cooperação em Ciência. Tecnologia e Inovação. Desenvolvimento Local.

\section{Innovation, development and physical education: the triple helix argument}

\begin{abstract}
This study analyzes the data on the Science and Technology Ministry of Brazil's Portal for Innovation. The aim is to understand the process of the physical education innovation. We use the argument triple helix as theoretical framework to evaluate the synergy between university-industry-government in the physical education's field of research. The methodology was guided by the literature and document's research. The results allow us to infer that the area of physical education research is typically multidisciplinary. There is a significant number of researchers and research groups, however, there are no related industries. The non-participation of the industries indicates that physical education is far from the productive sector, which highlights the today's inability to raise funds for the survey of this sector, and involve it in schemes that enable innovation and development projects from research activities.
\end{abstract}

Key Words: Physical Education. Policies and Cooperation in Science. Technology and Innovation. Local Development.

\section{Introdução}

O estudo de Silva; Terra; Votre (2006) introduziu o argumento da hélice tríplice $(\mathrm{HT})$ no contexto da educação física brasileira. As reflexões que ali se construíram aproveitaram o debate que vem sendo desenvolvido em relação ao papel da universidade no novo cenário mundial; principalmente, por conceder-lhe posição de destaque no desenvolvimento social $e$ econômico das regiões.

$\mathrm{O}$ argumento da HT aduz a tese de que a universidade tem um papel preponderante na sociedade baseada em conhecimento (ETZKOWITZ; LEYDESDORFF, 2000). Outros modelos preconizam as empresas/indústrias como líderes na inovação (LUNDVALL, 1992; NELSON, 1993) ou o Estado (SÁBATO; MACKENZIE, 1982).
O modelo HT propõe que as universidades preparem profissionais para promoverem a inovação e o desenvolvimento. Os governos devem contribuir com a criação, aperfeiçoamento e consolidação de políticas públicas, com mecanismos de fomento a essas ações. As empresas integram o esquema, com base na responsabilidade social, como parceiras dos dois outros atores (SILVA; TERRA; VOTRE, 2006).

O objetivo deste trabalho é analisar o contexto da pesquisa em educação física no Brasil, no que concerne à sinergia entre universidade-empresagoverno. Busca-se responder a seguinte questão: qual é o cenário da pesquisa em educação física no Brasil, quando se focaliza a sinergia entre a universidade, o governo e a empresa em relação à inovação e ao desenvolvimento local? 
Dados coletados no Portal Inovação ${ }^{1}$, do Ministério de Ciência e Tecnologia, foram utilizados para mapear o cenário que envolve a área de pesquisa em educação física e suas relações com outros setores no Brasil.

Há de se esclarecer que se entende por pesquisa em educação física, para efeito das discussões levantadas neste trabalho, todos os estudos que utilizam como uma de suas palavraschave o termo "educação física" e que basicamente estão relacionados com: desporto, escola, lazer, gestão esportiva, projetos sociais esportivos, iniciação às atividades do movimento, ilustrados por dança, lutas, brincadeiras, jogos coletivos e individuais, atividades de contato com a natureza e com a cultura.

O termo inovação é compreendido neste trabalho como um processo que abarca atividades técnicas, gestão, concepção, que resultam na criação ou aperfeiçoamento de produtos ou de processos.

\section{Metodologia}

Este trabalho apresenta uma abordagem híbrida, quali-quantitativa; pois, a partir de dados estatísticos coletados no Portal da Inovação, procedeu-se a uma análise qualitativa, com base no referencial teórico obtido na pesquisa bibliográfica. Em relação aos objetivos, trata-se de um estudo exploratório.

$\mathrm{Na}$ análise dos dados do Portal da Inovação, utilizaram-se elementos da estatística descritiva, no sentido de sintetizar uma série de valores de mesma natureza e obter uma visão global da variação desses valores, principalmente, por meio de tabelas e de gráficos (BARBETTA, 1998).

A coleta foi realizada no Portal da Inovação no dia 20 de novembro de 2008. Três partes foram examinadas: especialistas, grupos de pesquisa e empresas, utilizando-se a palavra-chave: "educação física", entre aspas. O quesito especialista, segundo a classificação do Portal, engloba todos aqueles que se envolvem com a pesquisa na área da educação física e que estão cadastrados na Plataforma Lattes: graduados, especialistas lato sensu, mestres e doutores, em qualquer área do conhecimento. Os especialistas se distribuem por unidades da federação, por titulação máxima e por área de titulação. Quanto aos grupos de pesquisa, os dados coletados referem-se aos grupos por unidades da federação e por área do conhecimento. O último item referese às empresas envolvidas em parcerias com a educação física em projetos de pesquisa, desenvolvimento e inovação.

\footnotetext{
${ }^{1}$ http://www.portalinovacao.mct.gov.br/pi/
}

\section{Hélice tríplice e a sinergia entre universidade-empresa-governo no Brasil}

Com a abertura política no Brasil, o desmonte da guerra fria, a diminuição da influência militar houve um redesenho nas relações entre universidade, empresa e governo. Percebeu-se, claramente, uma preocupação em aproximar a universidade da empresa.

Entretanto, de acordo com Dagnino (2004), com base numa visão neoliberal, o governo Cardoso não tinha intenção de destinar recursos adicionais para a pesquisa e para as instituições de ensino superior. Por conseguinte, a comunidade de pesquisa nacional não se dispôs a estreitar os laços com as empresas.

Desse impasse, surgiram e surgem ações que vêm tentando estimular a criação de empresas por parte de pesquisadores e as já existentes a enveredarem pelo caminho da pesquisa com fomento governamental, haja vista o surgimento da Lei de Inovação, Lei do Bem, Fundos Setoriais e outros mecanismos.

No governo Lula, mesmo com a manutenção de vários postulados do governo anterior, no que se refere à destinação de recursos para a pesquisa, tem havido maior preocupação e investimento. De acordo com Vieira (2008), o governo federal, em 2008, investiu $1.11 \%$ do Produto Interno Bruto (PIB) em pesquisa, desenvolvimento e inovação; a meta para 2010 é investir $1.50 \%$ do PIB.

Dados do Sistema Integrado de Informações Financeiras $(\text { Siafi })^{2}$ mostram que o Ministério da Educação no Brasil, em 2008, teve uma dotação no orçamento atrás apenas do Ministério da Defesa e do Ministério da Saúde. Apesar de o governo ter executado apenas $27,5 \%$ do orçamento previsto, os números orçamentários dão a dimensão da importância da área no contexto atual do país.

Os efeitos dessa reorganização vêm sendo sentidos nas ações realizadas pelos órgãos governamentais de avaliação e de fomento às ações educacionais. À responsabilidade de ensino e pesquisa, acrescentou-se uma terceira missão da universidade: a extensão.

No Brasil, a extensão foi entendida, inicialmente, como uma forma filantrópica de ação junto às comunidades mais necessitadas. Entretanto, a concepção atual vai muito além de uma visão assistencialista. Não é de surpreender o crescimento de incubadoras (ALMEIDA, 2008), empresas juniores e agentes de inovação nas

\footnotetext{
${ }^{2}$ http://www.tesouro.fazenda.gov.br/SIAFl/index.asp
} 
universidades brasileiras (SENHORAS, 2008). O papel de efetivar a transferência de conhecimento para a sociedade tem sido absorvido pela universidade.

No campo da educação física, por exemplo, o impacto e o legado de megaeventos esportivos receberam atenção especial por parte do governo. Em 2007, a Prefeitura Municipal do Rio de Janeiro solicitou ao Grupo de Estudos Olímpicos da Universidade Gama Filho que avaliasse os Jogos Panamericanos de 2007, no sentido de verificar o que os jogos poderiam deixar como legado para a cidade (TERRA; DACOSTA, 2008).

Com efeito, configura-se um novo quadro, no qual a universidade exerce sua função no ensino e na pesquisa, como concebida tradicionalmente. No entanto, a sinergia que foi produzida entre governo e universidade, por exemplo, no caso demandado pela Prefeitura do Rio de Janeiro, levou a universidade a basear o seu programa de pós-graduação não apenas para o ensino e a pesquisa.

A transferência de ciência e tecnologia à sociedade torna-se fundamental para incorporar conhecimento à própria universidade, mas, principalmente, para a sociedade, empresas e governo. Portanto, a indissociabilidade entre ensino, pesquisa e extensão e a transferência de conhecimento criam o ambiente propício para que as três pás da hélice (universidade-empresagoverno) atuem de forma a favorecer o movimento cíclico, espiral, cumulativo e contínuo do processo criativo e inovador (ETZKOWITZ; LEYDESDORFF, 1995; ETZKOWITZ et al., 2000; ETZKOWITZ, 2005; LEYDESDORFF; MEYER, 2006)

Entretanto, estamos longe de realizar esta transferência de conhecimento de forma efetiva. A pressão governamental para que a universidade e os centros universitários cumpram o seu papel com a pesquisa é enorme, ou seja, a universidade brasileira ainda se encontra na primeira revolução acadêmica, restando um grande espaço a ser conquistado para atingir o que preconiza a segunda revolução.

\section{As revoluções acadêmicas}

A primeira revolução acadêmica deu-se com a incorporação da pesquisa às funções de ensino realizadas pela universidade (ETZKOWITZ, 1990). No Brasil, de acordo com Almeida (2008), a incorporação da pesquisa pela universidade ocorreu nos anos 1970, num contexto em que o regime militar impunha o direcionamento dos estudos. Não houve, portanto, a necessária autonomia para que a universidade pudesse estabelecer elos mais fortes com a sociedade.
Passados mais de trinta anos, temos uma realidade nacional que ainda mostra a necessidade de a universidade, principalmente a privada, implementar efetivamente a primeira revolução acadêmica.

A segunda revolução acadêmica surge a partir da necessidade de um novo modelo de universidade que abarque uma função além da pesquisa e do ensino, a saber: produção e comercialização dos resultados da pesquisa científica. A interação da universidade com a empresa recebe, então, a denominação de segunda revolução acadêmica (ALMEIDA, 2008).

Não obstante, no Brasil, a segunda revolução acadêmica tem se desenvolvido não somente no campo econômico, mas, principalmente, no campo social. As universidades têm, por meio da área de extensão, estabelecido uma preocupação com o entorno e com uma visão crítica de desenvolvimento.

No caso brasileiro, em virtude das demandas sociais, há na universidade uma bifurcação das redes de interação dos principais atores. Vê-se por um lado um viés de modernização, com base em padrões internacionais, na dinâmica da hélice tríplice tradicional; e, por outro, um viés crítico de forma a permitir a inclusão social no formato de uma hélice tríplice público-social (SENHORAS, 2008).

\section{A evolução do modelo hélice tríplice}

De acordo com Etzkowitz e Leydesdorff (2000) o modelo HT1 (Triple Helix 1) apresenta uma configuração semelhante ao proposto no triângulo de Sábato (1975), em que o governo engloba a universidade e a empresa, direcionando a relação entre eles (Figura 1). Um exemplo deste modelo foi largamente utilizado por países socialistas do Leste Europeu e na antiga União Soviética. A HT1 é apresentada por esses autores como uma configuração estática.

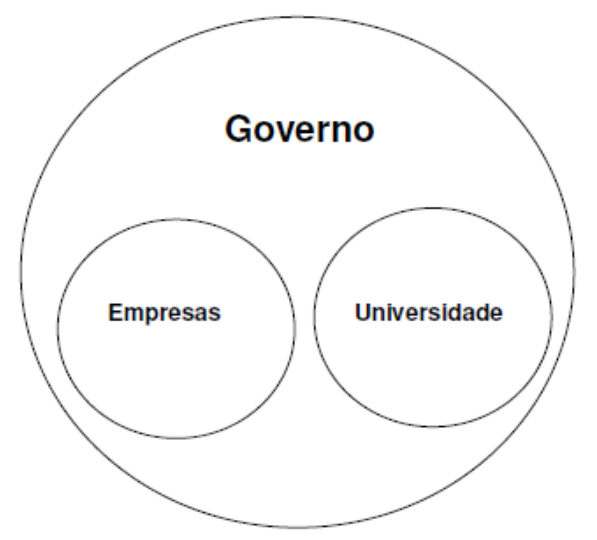

Figura 1. Modelo estático de relações entre universidade-empresa-governo. Fonte: adaptado de Etzkowitz; Leydesdorff (2000).

O segundo modelo, a HT2 (Triple Helix 2), apresenta um distanciamento entre a universidade, a empresa e o governo. Configura- 
se como um modelo laizzez-faire. As instituições apresentam-se com bordas bem definidas e sem interação. De certa forma, as pás da hélice produzem um movimento no desenvolvimento econômico e social, mas atuam isoladamente (Figura 2).

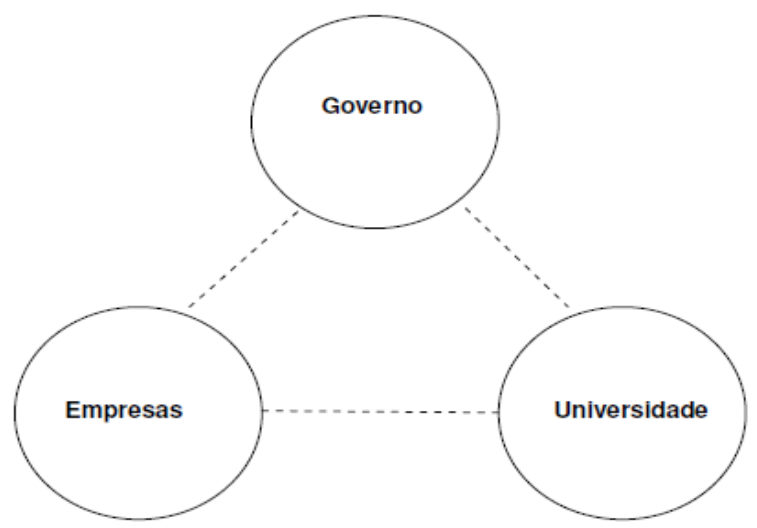

Figura 2. Modelo laizzez-faire de relações entre universidade-empresa-governo. Fonte: adaptado de Etzkowitz; Leydesdorff (2000).

O terceiro modelo, e o que até o momento vem sendo utilizado com mais ênfase para explicar a mudança paradigmática da sociedade industrial para a sociedade do conhecimento é a HT3 (Triple Helix 3). Neste caso, a interação entre as três pás se realiza de forma efetiva, promovendo uma infra-estrutura de conhecimento que alicerça o desenvolvimento das regiões. As relações que se processam neste modelo permitem que as instituições possam também exercer o papel da outra, produzindo organizações híbridas que emergem das interfaces (Figura 3).

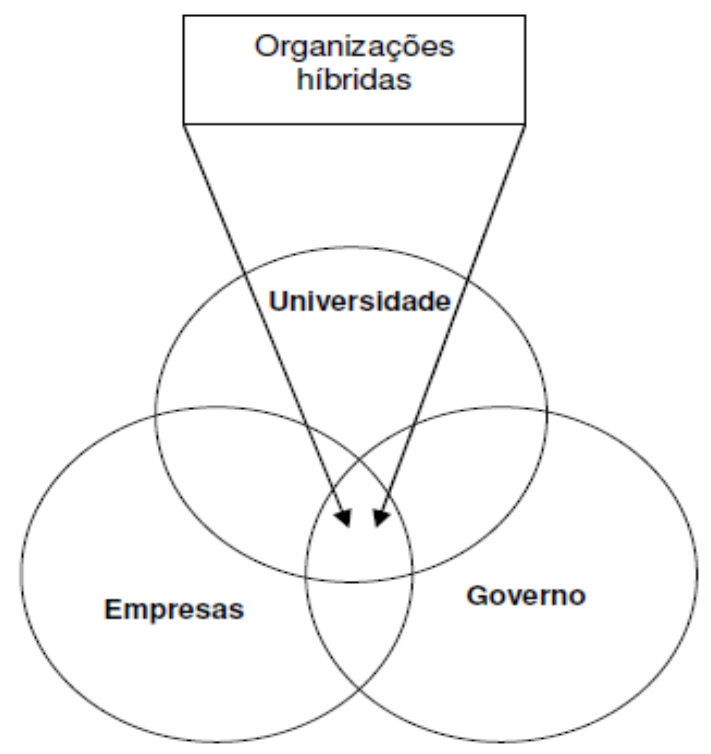

Figura 3. Modelo da hélice tríplice de relações entre universidade-empresa-governo. Fonte: adaptado de Etzkowitz; Leydesdorff (2000).
O governo brasileiro tem buscado encorajar uma ambiência inovadora através de incentivos fiscais, fundos setoriais, legislações de incentivo à pesquisa, ao esporte, à cultura etc. Assim, o seu papel de controlador tem sido enfraquecido para dar lugar ao de incentivador das ações de inovação.

Entretanto, as diferentes pressões sociais da sociedade civil organizada têm levado os teóricos do modelo HT a pensarem numa perspectiva substantiva além da já tradicional perspectiva instrumental. Ou seja, as preocupações com os valores e com um desenvolvimento sustentável têm se igualado às preocupações econômicas. A inovação implica não apenas o desenvolvimento econômico e social, mas também o meio ambiente, o planeta, a vida.

Nesse sentido, Etzkowitz \& Zhou (2006) desenvolveram o modelo de hélices tríplices gêmeas (triple helix twins), incorporando uma dimensão crítica ao modelo tradicional. Em determinados contextos, a empresa pode estar muito enfraquecida, às vezes é até inexistente; neste caso, outras instituições podem substituí-la (Figura 4). Entender a dinâmica da inovação em relação à sustentabilidade é o ponto principal adicionado à estrutura da HT tradicional. Assim teríamos a HT tradicional (universidade-empresagoverno) e a HT twins ou sustentável (universidade-público-governo) que se complementariam.

Senhoras (2008) utiliza o termo hélice tripla público-social para se referir à $\mathrm{HT}$ twins ou sustentável. No modelo da HT público-social, o formato estratégico pressupõe, por exemplo, que - sistema público de pesquisa e de ensino superior (SPPES) "deve responder às necessidades sociais específicas de forma ativa, com preocupação e comprometimento da agenda de ensino, pesquisa e extensão para a solução de problemas locais, regionais e nacionais de inclusão social" (p. 142).

A dimensão público-social é acrescentada ao modelo tradicional. Trata-se da incorporação das demandas da sociedade, de suas aspirações, incertezas, necessidades e também do seu ponto de vista. As redes que se constroem nas diversas interações sociais são o tecido crítico que confeccionam o modelo de HT público-social.

A metáfora rede tem sido utilizada com sucesso para visualizar o processo interativo entre atores que buscam se articular em espaços, de modo a construírem uma sinergia que promova o conhecimento. 


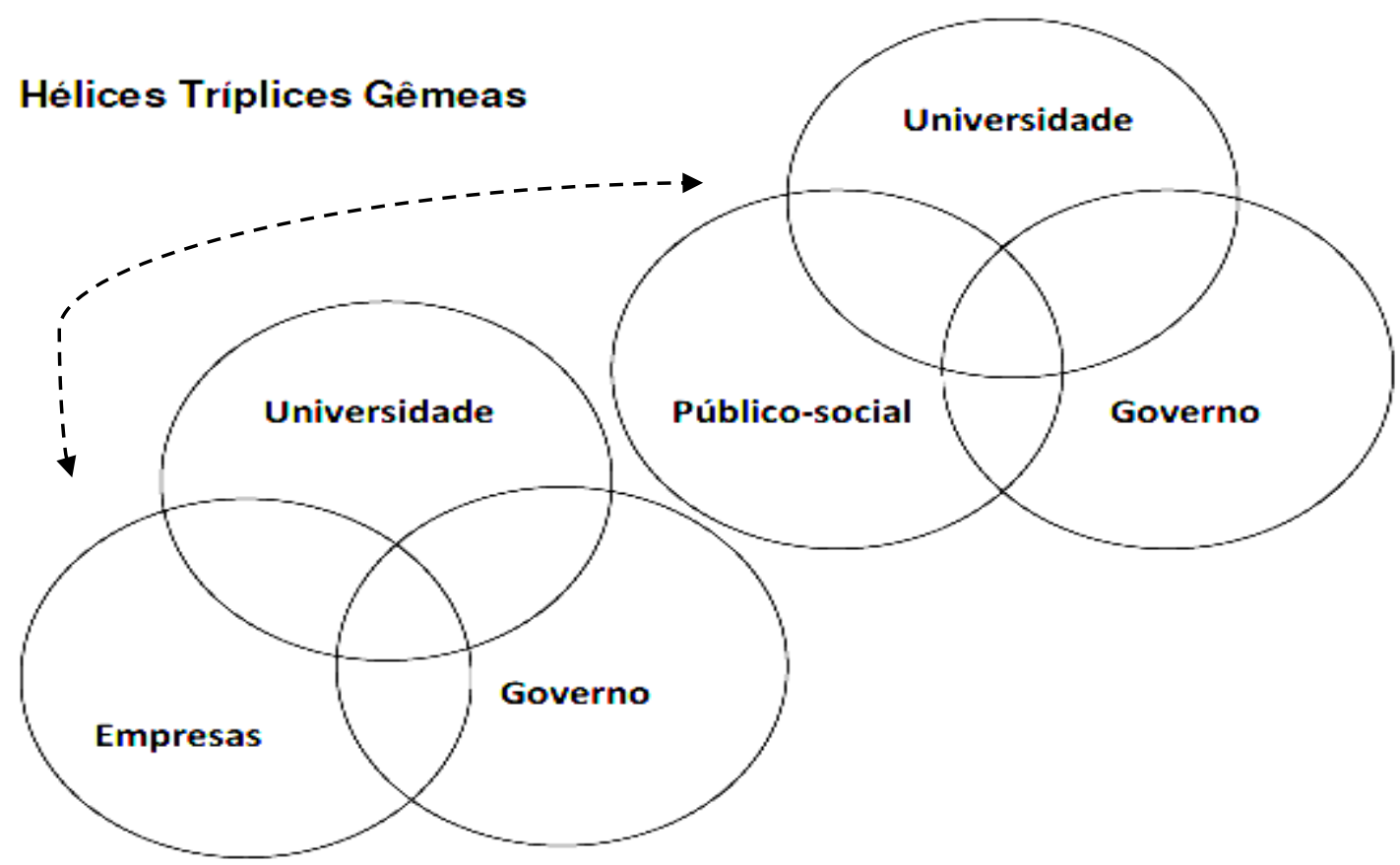

Figura 4. Modelo de hélices tríplices gêmeas. Fonte: própria

A noção de representação espacial e de conjunto articulado de atores implica uma conexão de espaços ou de atores (SENHORAS, 2008). A principal finalidade das redes sejam elas sociais, econômicas, científicas, comerciais etc., é a construção de um conhecimento compartilhado entre diversas áreas, transformando um saber tácito em explícito. Desta forma, produz-se um capital (social, econômico, esportivo, cultural), que serve de base para o desenvolvimento de regiões. As redes geram, assim, uma ambiência favorável ao conhecimento.

O fenômeno da inovação, por meio de redes, pode ser sintetizado através dos seguintes modelos de análise: 1) Sistema Nacional de Inovação, onde a empresa tem o papel preponderante no desenho de governança (LUNDVALL, 1992; NELSON, 1993); 2) Triângulo de Sábato, onde o Estado é o principal ator (SÁBATO, 1975); 3) Hélice Tríplice Tradicional (HT3), onde a universidade empreendedora é a protagonista (ETZKOWITZ \& LEYDESDORF, 1995, 2000); 4) Hélice Tríplice Twins (Sustentável ou Público-Social), onde universidade e a sociedade, com forte apoio estatal e por meio de institutos públicos de pesquisa e do sistema público de pesquisa e de ensino superior exercem a liderança (ETZKOWITTZ; ZHOU, 2006; SENHORAS, 2008).

\section{O portal da inovação}

O Ministério de Ciência e Tecnologia do Brasil (MCT), em outubro de 2005, inaugurou o Portal da Inovação, que tem por objetivo reunir informações sobre especialistas, grupos e empresas envolvidas com pesquisa no Brasil. Trata-se de um trabalho pioneiro no país, realizado a partir de dois componentes metodológicos e instrumentais que o antecederam: o Projeto INVENTEC e a Plataforma Lattes, do CNPq. Essa iniciativa do MCT visa a aproximar empresas, universidades e centros de pesquisa em prol da inovação ${ }^{3}$. O portal é continuamente atualizado, com base na Plataforma Lattes de currículos e nos dados dos grupos de pesquisa.

A Lei de Inovação (Lei no 10.973 de 02/12/2004) estabelece medidas de incentivo à inovação e à pesquisa científica e tecnológica. Inspiradas na lei, várias ações têm sido empreendidas, entre elas a criação do Portal da Inovação do MCT, que tem por missão promover o encontro de competências e de oportunidades e estabelecer um espaço para cooperação entre os diversos atores envolvidos com a cadeia de inovação. Dessa forma, visa-se à produção de estratégias e o desenvolvimento de projetos de cooperação envolvendo Empresas, Comunidade Técnico-Científica, Instituições de Ciência, Tecnologia e Inovação (ICTIs) e Organizações de Apoio, de forma a estimular a cooperação nos setores sócio-econômicos nas diversas áreas do

3 Sempre que for referido em termos genéricos, o termo inovar, inovação está associado a "introduzir novidade; fazer algo como não era feito antes”, conforme Houaiss eletrônico. 
conhecimento, com vistas a promover a inovação e o desenvolvimento local e regional.

O objetivo de mapear o Portal da Inovação, focalizando alguns dados que estão disponibilizados à consulta pública, é no sentido de explorar as possibilidades de sua utilização na promoção do intercâmbio de informações valiosas para o incremento da pesquisa na área de educação física. Observou-se a sinergia entre universidade, empresa e governo, no tocante à participação da educação física na promoção da inovação e do desenvolvimento no país.

Desde a Constituição Federal de 1988 (art. 218), o Estado busca promover e incentivar o desenvolvimento científico e tecnológico, a pesquisa e a capacitação tecnológica. As pesquisas científicas e tecnológicas recebem tratamento prioritário de modo a desenvolver o país. Além disso, o Estado incentiva a formação de recursos humanos nas áreas de ciência, pesquisa e tecnologia, com condições especiais de trabalho. Um ponto a ser destacado é que a lei apoia as empresas que investem em pesquisa, facultando aos estados e ao Distrito Federal vincular parcela de sua receita orçamentária a entidades públicas de fomento ao ensino e à pesquisa.

A legislação que criou os fundos setoriais pode ser considerada o marco legal da Ciência, Tecnologia e Inovação (C\&T\&l) no Brasil, uma vez que modificou a forma de financiamento da pesquisa, estabelecendo novo padrão de estímulo ao fortalecimento do sistema nacional de inovação. Seu objetivo é garantir a estabilidade de recursos para a área e criar um novo modelo de gestão, com a participação de vários segmentos sociais, além de promover maior sinergia entre as universidades, centros de pesquisa, o setor produtivo e os governos locais. Criados a partir de 1999, eles podem ser considerados atualmente os maiores instrumentos de financiamento de projetos de pesquisa, desenvolvimento e inovação no Brasil. A lista dos 16 fundos ora em operação é a seguinte: petróleo, energia elétrica, recursos hídricos, transportes, mineração, espacial, tecnologia da informação, infra-estrutura, saúde, agro-negócio, verde-amarelo, biotecnologia, setor aeronáutico, telecomunicações, transporte aquaviário, construção naval e Amazônia. Dois deles são transversais: o verde-amarelo, voltado à interação universidade-empresa, e o de infraestrutura que apoia a melhoria da infraestrutura das instituições.
Os fundos setoriais têm se constituído no principal instrumento do Governo Federal para alavancar o sistema de Ciência, Tecnologia e Inovação (C\&T\&I). Eles têm possibilitado a implantação de milhares de novos projetos de pesquisa em instituições de ciência e tecnologia e objetivam não somente a geração de conhecimento, mas também sua transferência para empresas. Projetos em parceria com 0 governo e a universidade têm estimulado maior investimento em pesquisa por parte das empresas.

A lei de inovação, de 2 de dezembro de 2004, regulamentada pelo Decreto 5.563, de 11 de outubro de 2005, facilita a interação entre as universidades, instituições de pesquisa e o setor produtivo. Ela está organizada em torno de três eixos: a constituição de ambiente propício a parcerias estratégicas entre as universidades, institutos tecnológicos e empresas; o estímulo à participação de institutos de ciência e tecnologia no processo de inovação e, por fim, o estímulo à inovação na empresa.

Outra lei vinculada a essa questão é a Lei 11.196/2005, chamada Lei do Bem, tem o propósito de estimular as exportações, através da redução de impostos e do incentivo à pesquisa. Seu objetivo central é o estímulo à pesquisa e desenvolvimento, encorajando o emprego e induzindo à criação de micro e pequenas empresas formadas por pesquisadores.

Ao se analisar os fundos setoriais e demais legislações, verifica-se que a área de educação física não é contemplada de forma genérica e muito menos de forma específica. Urge, portanto, que a comunidade acadêmica assuma uma atitude reflexiva, crítica e criativa, no sentido de formular propostas de pesquisa inovativa. Nos casos em que já tem contribuições dignas de serem mostradas aos organismos de suporte e parceria, é necessário divulgar a contribuição que as pesquisas em educação física podem trazer para o desenvolvimento local e regional.

\section{Resultados e Discussão Os especialistas}

A partir da consulta ao Portal da Inovação utilizando-se a palavra-chave "educação física", foram constatados 11731 especialistas de diferentes áreas e 1335 grupos de pesquisa. Não foram encontradas empresas envolvidas com pesquisa utilizando-se esse descritor (Figura 5). 


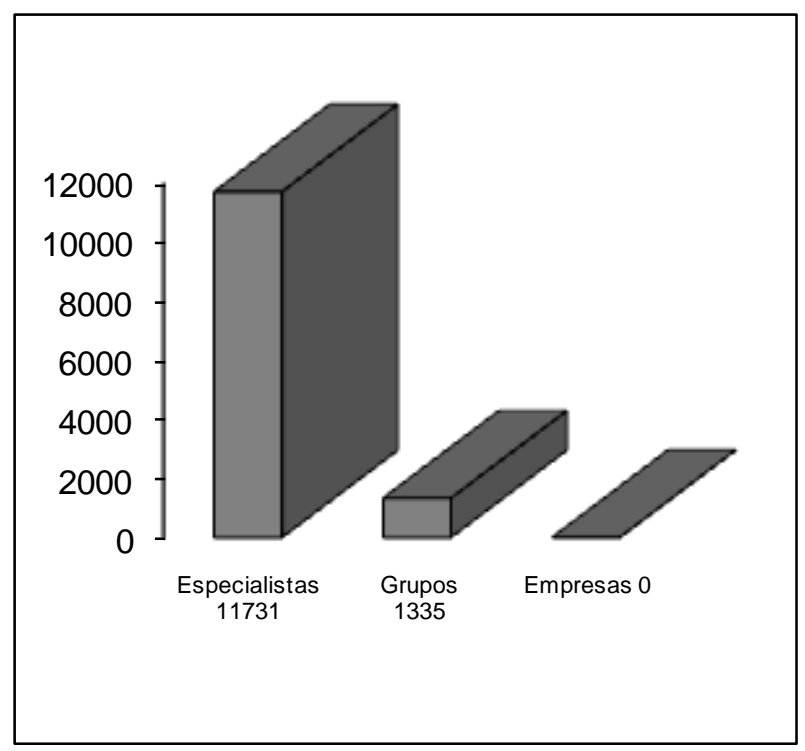

Figura 5. Educação Física: especialistas, grupos e empresas. Fonte: Portal da Inovação - Acesso em: 20/11/2008.

Em relação ao número de especialistas por unidades da federação, verifica-se que São Paulo, Paraná e Rio Grande do Sul concentram quase a metade do efetivo brasileiro. Comparando-se dados coletados em 2008 (Figura 6) com os de 2006 (Figura 7), percebe-se um avanço significativo em Minas Gerais, Mato Grosso do Sul e Pará.

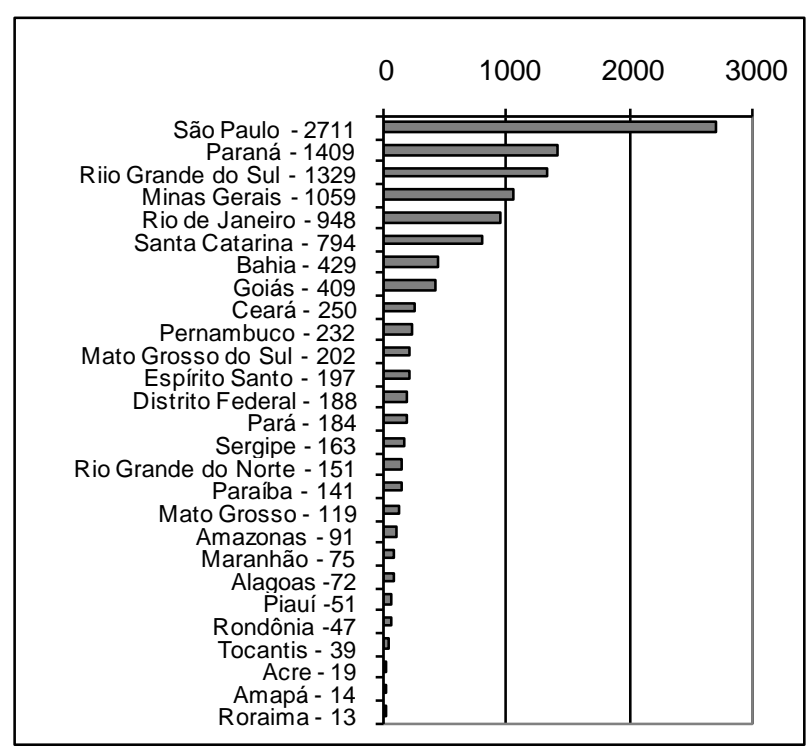

Figura 6. Especialistas por unidades da federação. Fonte: Portal da Inovação. Acesso em: 20/11/2008.

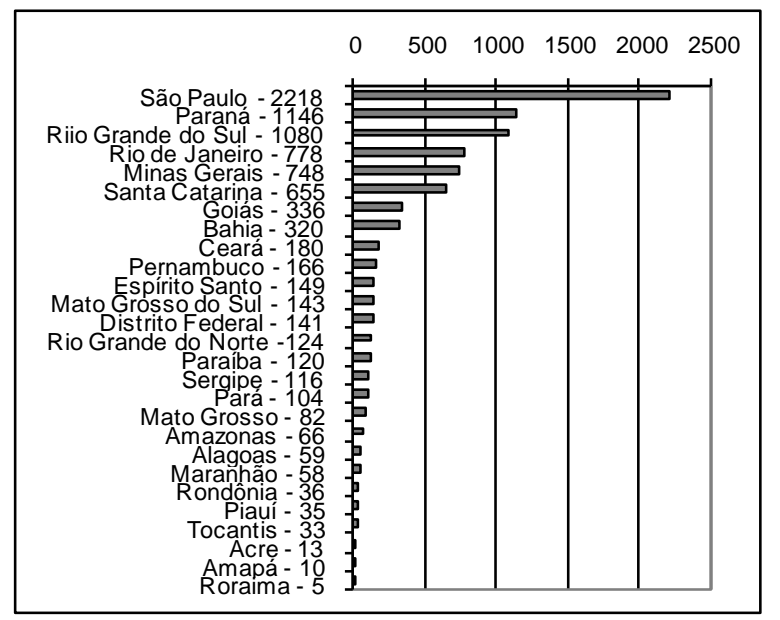

Figura 7. Especialistas por unidades da federação. Fonte: Portal da Inovação. Acesso em: 30/12/2006.

Por região, verifica-se um predomínio do sudeste e do sul na concentração de especialistas, que estão assim distribuídos: região sudeste $(42 \%)$, região sul $(30 \%)$, região nordeste $(13 \%)$, região centro-oeste $(8 \%)$ e região norte (4\%) (Figura 8).

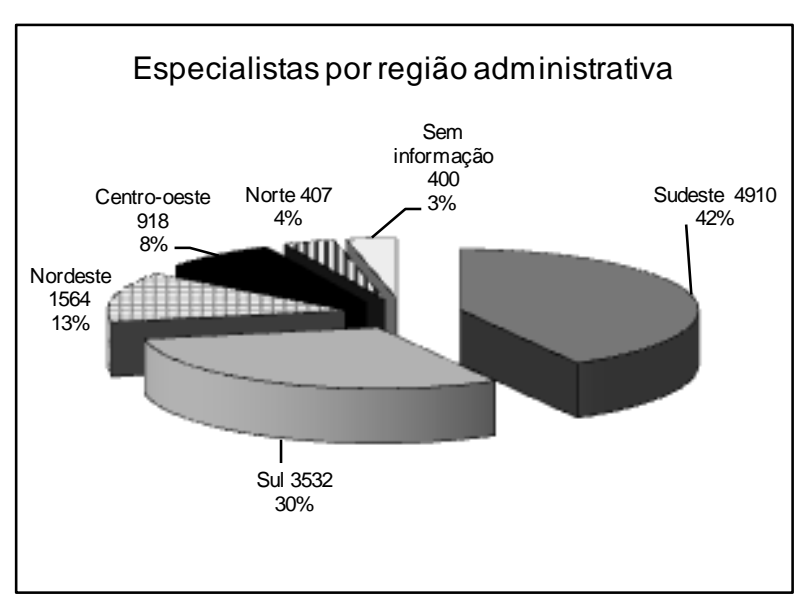

Figura 8. Especialistas por região administrativa. Fonte: Portal da Inovação. Acesso em: 20/11/2008.

Em relação à titulação máxima, os especialistas estão divididos entre os que possuem o título de mestrado - 3385 (29\%); especialização - 2775 (24\%); doutorado - 2461 (21\%); graduação - 1899 $(16 \%)$ e outros que não se enquadraram nas categorias anteriores ${ }^{4}-1221$ (10\%) (Figura 9).

\footnotetext{
${ }^{4}$ Parece relativamente alto o número englobado em "outros", e que merece investigação suplementar.
} 


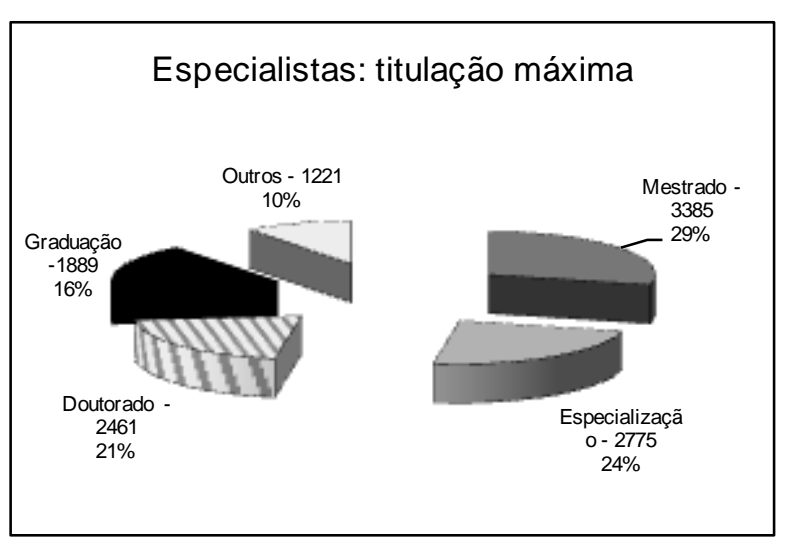

Figura 9. Especialistas: titulação máxima. Fonte: Portal da Inovação. Acesso em: 20/11/2008.

Verifica-se um número equilibrado entre doutores, mestres e portadores do título de especialização. Esperaríamos mais doutores, menos mestres e pouquíssimos com especialização. O gráfico ilustra o caráter recente da educação física na área da pesquisa e inovação, pois o número de doutores é praticamente equivalente ao de portadores de especialização. Por outro lado, é muito alto o número de graduados.

Os especialistas que atuam em pesquisa em educação física provêm de muitas áreas do conhecimento: educação, psicologia, medicina, saúde coletiva, fisioterapia, terapia ocupacional, fisiologia, história, sociologia, engenharia de produção, comunicação, nutrição, enfermagem, filosofia e letras, entre outras, conforme se pode ver a seguir (só listamos áreas com 50 ou mais representantes).

Tabela 1. Especialistas por área de titulação. Fonte: Portal da Inovação. Acesso em: 20/11/2008.

\begin{tabular}{|c|c|}
\hline Especialistas por área de titulação & Frequência \\
\hline Educação Física & 3906 \\
\hline Educação & 2376 \\
\hline Psicologia & 297 \\
\hline Medicina & 201 \\
\hline Fisioterapia e Terapia Ocupacional & 151 \\
\hline Saúde Coletiva & 147 \\
\hline Fisiologia & 140 \\
\hline História & 106 \\
\hline Engenharia de Produção & 103 \\
\hline Sociologia & 102 \\
\hline Enfermagem & 74 \\
\hline Comunicação & 74 \\
\hline Administração & 72 \\
\hline Nutrição & 69 \\
\hline Letras & 64 \\
\hline Filosofia & 57 \\
\hline Odontologia & 52 \\
\hline Artes & 50 \\
\hline
\end{tabular}

No âmbito de co-atuação das muitas disciplinas, as forças de separação, dispersão e aniquilação continuam a desencadear-se. Mas, quase que concomitantemente, manifestam-se forças de religação, organizando novos grupos e núcleos a partir de elementos que se encontravam na periferia. Desta forma, uma dialógica indissociável está presente entre as forças que separam, dispersam, aniquilam e o que religa, integra e associa. Neste contexto, os grupos de pesquisa desempenham um papel decisivo na exploração, organização e consolidação de temas que interagem e se combinam de maneira, à primeira vista antagônica e concorrente, mas de fato, complementar.

\section{Os grupos de pesquisa}

Os grupos de pesquisa têm, dentre outras, a função de promover a integração e associação de especialistas em núcleos de discussão que garantam o surgimento e o desenvolvimento coerente e coeso de linhas de pesquisa. Seis estados concentram a maioria dos grupos, com São Paulo em liderança absoluta. Dos 1335 grupos, 411 grupos estão em São Paulo, 179 no Rio Grande do Sul, 136 no Paraná, 120 no Rio de Janeiro, 87 em Santa Catarina, 82 em Minas Gerais, 48 na Bahia, 35 no Ceará, 30 no Distrito Federal, 30 em Goiás, 26 na Paraíba, 26 em Pernambuco, 24 em Mato Grosso do Sul, 22 no Rio Grande do Norte, 13 em Mato Grosso, 11 no Amazonas, 10 em Sergipe, 9 no Espírito Santo, 8 no Pará, 7 no Tocantins, 6 em Alagoas, 5 em Rondônia, 5 no Piauí, 2 no Acre, 2 no Maranhão e 1 no Acre.

Em relação à área de conhecimento desses grupos, verifica-se que a prevalência dos estudos sobre educação física encontra-se na área mais ampla de educação (32,17\%). A seguir, vem a área da educação física $(19,44 \%)$. Tal distribuição é compreensível, se pensarmos que nos programas de pós-graduação em educação, sobretudo na dimensão escolar, desenvolve-se robusta produção sobre educação física. A psicologia (mais a psicologia social, supomos), em terceiro lugar, justifica-se pela interação da educação física com questões e problemas sócioindividuais, a exemplo das questões sobre agressão, competitividade e cooperação no esporte. A presença forte de saúde coletiva, medicina, nutrição, fisioterapia e enfermagem se explicam pelo enquadramento da educação física na grande área da saúde e, sobretudo, pelas conexões inevitáveis com o bem estar físico e mental das pessoas. Já história, sociologia, antropologia, comunicação, linguística e letras 
devem sua inclusão ao crescimento da subárea da educação física e cultura, na interface com o estudo das várias linguagens que nela se manifestam.

Tabela 2. Grupos e áreas de conhecimento (vinte primeiros). Fonte: Portal da Inovação. Acesso em: 20/11/2008.

\begin{tabular}{|l|c|}
\hline 1.Educação & 431 \\
\hline 2.Educação Física & 256 \\
\hline 3.Psicologia & 89 \\
\hline 4.Saúde Coletiva & 44 \\
\hline 5.Medicina & 38 \\
\hline 6.História & 33 \\
\hline 7.Física & 26 \\
\hline 8.Nutrição & 25 \\
\hline 9.Antropologia & 24 \\
\hline 10.Fisioterapia e Terapia Ocupacional & 24 \\
\hline 11;Sociologia & 23 \\
\hline 12.Comunicação & 20 \\
\hline 13.Enfermagem & 19 \\
\hline 14.Linguística & 18 \\
\hline 15.Fonoaudiologia & 16 \\
\hline 16.Fisiologia & 16 \\
\hline 17.Engenharia de Produção & 15 \\
\hline 18.Artes & 14 \\
\hline 19.Letras & 13 \\
\hline 20.Ciência da Computação & 13 \\
\hline
\end{tabular}

\section{Empresas}

Não encontramos empresas cadastradas no Portal da Inovação na área da educação física. Apesar de ser grande no país a presença de empresas envolvidas com 0 incentivo às atividades físicas, esporte, lazer, o portal mostra que há uma carência no investimento em pesquisa por parte das empresas nessa área.

A ausência das empresas pode também ser interpretada como sinal de pouca visibilidade da educação física, como área de inovação na produção do conhecimento, ou da consciência equivocada do empresário, sobre o que sua empresa pode ganhar, patrocinando a inovação nessa área.

A não participação da empresa poderia indicar também que a educação física está distante do setor produtivo. Tal afastamento, de certa forma, indicaria a sua incapacidade, hoje, em captar recursos junto às empresas, bem como envolvêlas em esquemas que viabilizem projetos de inovação e desenvolvimento a partir de ações de pesquisa.

Se pensarmos no mercado de equipamentos na área das academias de ginástica e nas múltiplas áreas dos esportes, a começar pelos esportes na natureza, seremos levados a admitir que a universidade possa estar perdendo uma excelente oportunidade de crescimento em pesquisa, por não estar competindo, de forma consequente, com os laboratórios das próprias empresas que, assim, substituem a universidade e preenchem a lacuna deixada por quem, em princípio, deveria estar presente nesse campo, interessante e promissor.

\section{Conclusão}

Os dados analisados a partir da consulta ao Portal da Inovação permitem inferir que a educação física vem se constituindo numa área de pesquisa que se poderia caracterizar como tipicamente multidisciplinar. Muitos dos pesquisadores que atuam em pesquisa em educação física provêm de diferentes áreas do conhecimento.

Num certo sentido, poder-se-ia argumentar que essa multiplicidade de áreas de titulação vem dando fôlego aos estudos desenvolvidos no campo da educação física. Por outro lado, a comunidade científica frequentemente reclama da falta de identidade acadêmica e de metodologias que permitam à educação física ganhar ou consolidar o status de "ciência". O mundo da educação física convive com o dilema de Morin (2006), "Um mundo só pode advir pela separação e só pode existir na relação do que é separado" (p. 31).

Com efeito, a participação de pesquisadores com diferentes tipos de formação vem impulsionando a educação física para caminhos que avançam sobre o ponto de vista das disciplinas separadas e articulam saberes de distinta fonte na produção do conhecimento. $O$ Portal da Inovação disponibiliza informações fundamentais para compreendermos 0 desenvolvimento da pesquisa e promovermos a interação entre os atores principais do processo de inovação.

Cabe ponderar que os programas de pósgraduação são inovativos por definição, uma vez que a eles se atribui a tarefa maior de produção de conhecimento relevante para a área. Por outra, destaque-se, que o conceito atual de inovação está pesadamente impregnado da idéia de agregar avanço tecnológico, e não da idéia da elaboração de novos produtos com as ferramentas disponíveis. Assim, alguns podem entender que seria difícil incluir no item inovação o que se vem fazendo na área acadêmica da educação física e cultura, em que se assiste a esforços na produção de novos manuais, com novos procedimentos de pesquisa e produção textual, novos livros de referência.

Há que se atentar também para o preenchimento dos grupos no Diretório de Grupos de Pesquisa do CNPq. Os programas de pósgraduação em educação física devem atrair e 
tornar visível a colaboração das empresas no desenvolvimento da pesquisa, do desenvolvimento e da inovação no Brasil, na área da educação física.

O país conta com múltiplas alternativas de fundos, programas, editais e linhas de suporte à pesquisa. Cabe-nos refletir sobre a participação da universidade, da empresa e do governo no desenvolvimento da pesquisa e inovação em nosso país. O modelo da hélice tríplice pode ser utilizado para avaliar a sinergia entre os protagonistas do desenvolvimento, pois focaliza efetivamente a espiral produzida na interação das três pás da hélice.

Cabe-nos refletir sobre o que podemos fazer face ao Fundo Verde-Amarelo, que tem como objetivos: incentivar a implementação de projetos de pesquisa científica e tecnológica cooperativa entre universidades, centros de pesquisa e o setor produtivo, e estimular a ampliação dos gastos em P\&D realizados por empresas.

Cabe-nos, também, posicionarmo-nos, como comunidade discursiva de pesquisa, face ao Fundo de Infra-Estrutura - CT/INFRA. Seu foco é modernizar e ampliar a infra-estrutura e os serviços de apoio à pesquisa desenvolvida em instituições públicas de ensino superior e de pesquisa brasileiras.

Este estudo utilizou o argumento da hélice tríplice como base para analisar a sinergia entre a universidade, a empresa e o governo no campo da pesquisa em educação física. Contatou-se que esses três atores estão ainda muito tímidos nesta área, necessitando de que se estabeleçam propostas que visem a criação de um espaço de consenso/dissenso, no sentido de aproximá-los e incentivá-los a trabalharem juntos.

Conforme a posição assumida neste trabalho, cabe à universidade o papel de líder nesta jornada. Assim, o espaço do conhecimento, que não é exclusivo da universidade, mas que a tem como referência no campo científico, ao ser aproximado do espaço do consenso/dissenso, pode efetivar um espaço de inovação, trazendo para a educação física a criação ou a melhoria de produtos ou de processos.

Desta forma, os programas de pós-graduação
em educação física podem contribuir
significativamente para a criação ou
aperfeiçoamento de produtos para atletas e
praticantes de atividades físicas e esportivas, tais
como: material técnico, equipamentos,
vestimentas, calçados, a partir de estudos
realizados no campo da biomecânica, com a
participação dos setores de desenvolvimento de

produtos das empresas. Equipamentos de musculação podem ser aperfeiçoados para a utilização de diferentes grupos esportivos, que possuam características específicas. Processos e metodologias podem ser criados ou aperfeiçoados a partir de estudos sócio-culturais em diferentes contextos. Programas de educação a distância podem ser oferecidos aos atletas para que, durante o período da vida profissional no esporte, possam também se preparar para o mercado de trabalho quando encerrarem suas carreiras esportivas. $O$ governo pode criar políticas que estimulem a aproximação das empresas com as universidades para atuarem na construção, gestão e desenvolvimento de parques esportivos. A universidade pode inaugurar pesquisas que estimulem a criação de áreas esportivas sustentáveis por parte de empresas, com incentivo governamental. O campo é fértil, no entanto, é preciso que a hélice de fato gire e produza a sinergia necessária para que sonhos se concretizem.

\section{Referências}

ALMEIDA, M. Innovation and entrepreneurship in Brazilian universities. International Journal of Technology Management and Sustainable Development, v. 7, n. 1, p. 39-58, 2008. Disponível em http://www.atyponlink.com/INT/doi/pdf/10.1386/ijtm.7.1.39 1?cookie Set=1 Acesso em: 20 set. 2009.

BARBETTA, P. A. Estatística aplicada às ciências sociais. Florianópolis: Editora da UFSC, 1998.

DAGNINO, R. A Relação Universidade-Empresa no Brasil e o "Argumento da Hélice Tripla".

Convergência, UAEM, México, n. 35, maioagosto, 2004. Disponível em http://www.finep.gov.br/revista brasileira inovaca o/quarta edicao/Dagnino.pdf Acesso em 20 set. 2009.

ETZKOWITZ, H. The Second Academic Revolution: The Role Of The Research University in Economic development. The Research System in Transition. S.E.Cozzens et al. (eds.), Kluwer Academic Publishers, Netherlands, p. 109124, 1990.

ETZKOWITZ, H. Reconstrução criativa: hélice tríplice e inovação regional. Rio de Janeiro: Inteligência Empresarial/Crie/Coppe/UFRJ, n. 23, 2005. Disponível em http://www.epapers.com.br/produtos.asp?codigo produto $=663$ Acesso em 20 set. 2009.

ETZKOWITZ, $\mathrm{H}$ et al. The future of the university and the university of the future: Evolution of Ivory Tower to Entrepreneurial Paradigm. Research 
Policy, Londres, v. 29, n. 2, 2000. Disponível em http://www.sciencedirect.com/science Acesso em: 20 set. 2009.

ETZKOWITZ, H.; LEYDESDORFF, L. The triple helix - university, industry, government relations: a laboratory for knowledge based economic development. In: The triple helix of university, industry, and government relations: the future location of research conference. Amsterdam, 1995. Disponível em http://users.fmg.uva.nl//leydesdorff/th1/index.htm Acesso em: 11 out. 2009.

ETZKOWITZ, H; LEYDESDORFF, L. The dynamics of innovation: from National Systems and "Mode 2" to a Triple Helix of universityindustry-government relations. Research Policy, Londres, v. 29, p. 109-123, 2000. Disponível em http://www.ingentaconnect.com/content/els/00487 333/2000/00000029/00000002/art00055 Acesso em: 20 set. 2009 .

ETZKOWITZ, H.; ZHOU, C. Triple Helix twins: innovation and sustainability. Science and Public Policy, v. 33, n. 1, February, p. 77-83, 2006. Disponível em http://www.ingentaconnect.com/content/beech/spp /2006/00000033/00000001/art00007 Acesso em: 12 out. 2008.

LEYDESDORFF, L; MEYER, M. Triple Helix indicators of knowledge-based innovation systems. Research Policy, v. 35, n. 10, December, 2006. Disponível em http://dlist.sir.arizona.edu/1490/ Acesso em: 01 out. 2008.

LUNDVALL, B. National Systems of Innovation. Pinter, London, 1992.

MORIN. E. O método 6: ética. São Paulo: Sulina, 2006.

NELSON, R. R. National Innovation Systems: a Comparative Analysis. Oxford Univ. Press, New York, 1993. Disponível em National Innovation systems. Acesso em: 12 jan. 2009.

\section{SÁBATO, J. El pensamiento latinoamericano en la problemática ciencia-technología- desarrollo-dependencia. Buenos Aires: Paidós, 1975.}

SÁBATO, J.; MACKENZIE, M. La Producción de Tecnología. Autónoma o Transnacional. Nueva Imagen, México, 1982.

SENHORAS, E. M. As redes do desenvolvimento Econômico e Social no Sistema de Ensino Superior Brasileiro. Liinc em Revista, v.4, n.1, p. 138-153, março, 2008. Disponível em http://revista.ibict.br/liinc/index.php/liinc/article/vie wFile/258/149. Acesso em: 12 set. 2009.

SILVA, C. A. F.; TERRA, B. VOTRE, S. J.. O modelo da hélice tríplice e o papel da educação física, esporte e lazer no desenvolvimento local. Revista Brasileira de Ciências do Esporte, Campinas, v. 28, n. 1, p. 167-183, set, 2006. Disponível em http://www.rbceonline.org.br/revista/index.php/RB CE/article/viewFile/45/53. Acesso em: 20 set. 2009.

TERRA, R.; DACOSTA, L. P. Antecedentes sobre a abordagem do tema Legados de Megaeventos Esportivos e respectivos desenvolvimentos para a produção da presente obra. In: DaCosta, L. P. et al. Legados de Megaeventos Esportivos. Brasília: Ministério do Esporte, 2008. Disponível em

http://www.confef.org.br/arquivos/legados/Livro.Le gados.de.Megaeventos.pdf. Acesso em: 11 set. 2009.

VIEIRA, A. C. G. Government support to innovation in Brazil. $7^{\text {th }}$ Biennial International Conference on University, Industry and Government Linkages. Glasgow: University of Strathclyde, 2009. Disponível em http://www.triplehelix-7.org/plenarypresentations/Triple\%20Helix Gadelha v1.pdf. Acesso em: 20 set. 2009.

Endereço:

Carlos Alberto Figueiredo da Silva Universidade Salgado de Oliveira e Centro Universitário Augusto Motta Rua Oscar Valdetaro, 94/1202 - Barra da Tijuca Rio de Janeiro RJ Brasil 22793-670

Telefone: (21) 24380824; (21)93283350

e-mail: ca.figueiredo@yahoo.com.br

Recebido em: 24 de setembro de 2009.

Aceito em: 22 de julho de 2010.

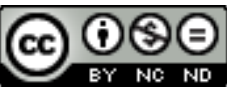

Motriz. Revista de Educação Física. UNESP, Rio Claro, SP, Brasil - elSSN: 1980-6574 - está licenciada sob Licenca Creative Commons 